\title{
Problematic Gaming Behaviour in Finnish Adolescents and Young Adults; Relation to Game Genres, Gaming Motives and Self-Awareness of Problematic Use
}

Niko Männikkö, 1 ,*

Phone +358 504096318

Emailniko.mannikko@oamk.fi

Joël Billieux, ${ }^{2}$

Email joel.billieux@uclouvain.be

Tanja Nordström, ${ }^{3}$

Email tanja.nordstrom@oulu.fi

Kaisa Koivisto, ${ }^{4}$

Emailkaisa.koivisto@oamk.fi

Maria Kääriäinen, 5

Email maria.kaariainen@oulu.fi

1 RDI services, Oulu University of Applied Sciences, Kiviharjuntie 8, FI-90220 Oulu, Finland

${ }^{2}$ Laboratory for Experimental Psychopathology, Psychological Sciences Research Institute, Catholic University of Louvain, Louvainla-Neuve, Belgium

3 Center for Life Course Health Research, Medical Research Center Oulu, University of Oulu, Oulu University Hospital and University of Oulu

AQ1

, Oulu, Finland 
4 School of Health and Social Care, Oulu University of Applied Sciences, Oulu, Finland

5 Research Group of Nursing Science and Health Management, Oulu University Hospital and University of Oulu, Oulu, Finland

\section{Abstract}

The aim of this study was to explore the relation between Problematic Gaming Behaviour (PGB) and specific psychological factors (gaming motives, self-awareness of problematic gaming behaviour) and structural factors (game genres) among Finnish adolescents and young adults. A national survey of 271 respondents, aged 13 to 24, participated in the study. The study sample was randomly selected from the Population Register Center. Multiple regression analysis was used as a means of examining links between game genres, gaming motives and PGB. In addition, pairwise comparisons of a non-problematic gaming behavior group and a problematic gaming behavior group were used as a means of examining differences across game genre use and self-awareness of PGB. PGB was particularly associated with the use of a group of games encompassing role-playing, progression (e.g., character development), action and strategy features. The findings indicated that entertainment-achievement, social and escapism motives were associated with PGB. On the whole, this study emphasized that specific game genres and playing motives are involved in problematic use of digital game playing.

\section{Keywords}

Gaming disorder

Game addiction

Problematic game play

Adolescent

Youth

Digital games

Game play motivations 
Digital games have become a major leisure activity in recent years, especially since the development of the Internet has allowed people to interact in multiplayer games that include elements of cooperation and competition. The growing popularity and frequency of digital game use has led to the emergence of clinical cases presenting symptoms of excessive use, and specialised treatment units have emerged to treat these disorders (Thorens et al. 2014). Growing evidence indeed suggests that the use of online games can become problematic and cause negative impacts on daily living, and that excessive users present symptoms that resemble those of addictive behaviour (Griffiths 2000; Grüsser et al. 2007; Kuss and Billieux 2017; Kuss et al. 2014).

The prevalence of videogame-related disorders has been reported to be between 1.7 to over 10\% of the population (Griffiths et al. 2012; Kuss et al. 2013), and it varies significantly as a function of culture (e.g., Asian vs. European countries) or age group (e.g., adolescents vs. young adults). The variation in prevalence rates may be at least partly due to discrepancies in the theoretical conceptualisation and measurement of PGBs (King et al. 2013; Kuss et al. 2014; Petry et al. 2014).

Moreover, the samples studied were often not representative (e.g. selfselected samples) and consequently they varied in terms of sample size and demographics. In 2013-notwithstanding inconsistencies in the conceptualisation and classification as well as limited evidence regarding the aetiology and natural courses of the disorder-"Internet Gaming Disorder" (IGD) was included in Section 3 of the Diagnostic and Statistical Manual of Mental Disorders as a tentative new psychiatric condition (American Psychiatric Association [APA] 2013; Petry and O'Brien 2013). This decision of the APA, which was aimed at generating research on that potential new clinical condition, already resulted in studies that have attempted to test and validate the tentative criteria proposed (Ko et al. 2014; Petry et al. 2014; Rehbein et al. 2015).

As the field being still characterised by theoretical and methodological debates regarding both the conceptualisation (Billieux et al. 2015a; Billieux et al. 2015b; Kardefelt-Winther 2014) and the measurement of the condition (Griffiths et al. 2016; van Rooij and Prause 2014; Van 
Rooij et al. 2016), the term Problematic Gaming Behaviour (PGB) will be used here to avoid any a priori conceptualisation (e.g., considering PGB as a genuine addictive disorder).

Individual differences exist regarding the gaming type preferences and platforms used (e.g., console vs. personal computer). Certain types of games are probably more likely to be associated with PGB than others, although to date, related evidence is scarce. Among the meagre existing data, a study by Elliott et al. (2012) showed that gamers who exhibited PGB preferred game genres such as first-person shooter (FPS), action adventure, roleplaying and online gambling (i.e., simulations of Poker, Black Jack and slot machine gambling). Other research shown that the prevalence of PGB increased in individuals playing video games involving aspects of role-playing, strategy, and action (Bailey, West \& Kuffel, 2013; Eichenbaum et al. 2015), or state (Bailey, West \& Kuffel, 2013). Recently, a study by Lemmens and Hendriks (2016) showed that individuals displaying PGB spent more time playing online role-playing and shooting games compared to healthy gamers.

AQ2

Among existing games, massively multiplayer online role-playing games (MMORPGs) are the ones for which evidence regarding PGB is the most robust (e.g., Kuss et al. 2012). MMORPGs allow hundreds or even thousands of gamers to play simultaneously, and include both collaborative (player versus environment $[\mathrm{PvE}]$ ) and competitive (player versus player [PvP]) features (Achterbosch et al. 2008). The addictive potential of MMORPGs has been linked to its socialising and reinforcing features, as well as the fact that the games take place in permanent virtual worlds (worlds that exist even when the player is not connected) and comprise an advancement system where players create a character (avatar) that is continuously evolving (Cole and Griffiths 2007; Kuss and Griffiths 2012). These above-mentioned characteristics have been proposed as structural factors promoting the high involvement in MMORPGs (e.g. Billieux et al. 2014; King et al. 2010).

Some studies have examined the characteristics of MMORPGs' gamers and gaming-related variables, and highlighted that the typical players 
are males aged in their early twenties, and that they play over $20 \mathrm{~h}$ per week (Nagygyörgy et al. 2013). A study by Smyth (2007) emphasized that MMORPGs played excessively may lead to worse health, poor sleep quality, difficulties in socialising in real life and poorer academic performance as compared with arcade, console or offline computer game players. Also, a study by Hellström et al. (2012) showed that the time devoted to MMORRPGs proved to be associated with negative health effects, in particular reduced sleep due the time spent gaming late at night.

Despite the above-mentioned evidence, recognition of a subclass of game types with certain game characteristics and reward features related to PGB is still somewhat open for further scientific debate (Donati et al. 2015; Elliott et al. 2012; Rehbein and Mößle 2013). Additionally, a recent study revealed that gaming versatility (e.g., a greater amount of video game genres played) can be seen as one factor associated with problematic gaming (Donati et al. 2015).

Notwithstanding the enormous academic interest in online games (Kuss and Griffiths 2012) and Internet-related disorders (Kuss et al. 2014; Lee et al. 2007), evidence regarding the differential addictive potential of distinct game genres is still scarce and further studies are required.

Existing studies support the view that certain gaming motives are more likely to be associated with PGB. A large body of evidence now establishes that the motives for playing MMORPGs are perceived to be a strong indicator of problematic online gaming (Billieux et al. 2014). In a seminal work, Richard Bartle formulated a theory that Multi-User Dungeon $\left(\mathrm{MUD}^{1}\right)$ players could be classified into four main types: killers, achievers, explorers and socialisers (Bartle 1996). Several years later, a study by Yee (2006) showed evidence that an individual's motivations for playing MMORPGs have an important impact on actual online gaming commitment. Yee (2006) proposed a model composed of three higher-order motives: achievement, social activity and immersion in a virtual environment. Each of these broad motives is subdivided into lower-order subcomponents (e.g. immersion can be divided into the subcomponents of role-playing, exploration or escapism). Among the motives identified by Yee, only achievement and escapism were systematic predictors of problematic use. Of note, a study by Billieux et 
al. (2013) revealed that Yee's motives predict actual in-game behaviour patterns (assessed through monitoring of a large sample of avatars from the game World of Warcraft-the world's most popular MMORPG to date). Regarding problematic use of MMORPGs, existing studies have shown connections between digital game addiction symptoms and specific motives, such as escapism (Billieux et al. 2011; Billieux et al. 2015c; Hellström et al. 2012) or immersion (Billieux et al. 2015c; Kneer and Glock 2013).

Although high involvement in digital games is not necessarily associated with negative outcomes, and thus has to be distinguished from dysfunctional or addictive use (Charlton and Danforth 2007), it appears that some individuals have difficulty realising when their involvement in video games becomes problematic, i.e., associated with functional impairment (King et al. 2009). However, to date, there is a lack of studies that try to determine if excessive players recognised and/or admitted the problematic nature of their involvement in video games, or if they tend to be characterised by denial. An exception is a study by Haagsma et al. (2012b)) which showed that only $16.7 \%$ of excessive gamers are aware of their problematic behaviour. It is still an open question why some players have difficulties admitting their PGB. Accordingly, it is worth conducting studies that further explore the association between PGB and self-awareness of problematic use.

Based on the evidence summarised, the objective of the current study is to explore the relation between Problematic Gaming Behaviour (PGB) and specific psychological factors (gaming motives, self-awareness of excessive use) and structural factors (game genres). Only limited data on this topic are available in Finland, although video game use in the country is ubiquitous - $74 \%$ of Finns at least occasionally play digital games (Mäyrä and Ermi 2014). Based on previous studies, the following hypotheses were formulated. Regarding game genre, we expect that roleplaying and especially the use of MMORPGs and shooting games will be associated more frequently with PGB than other types of video games. Regarding gaming motives, we predict that escapism- and achievement-related motives will be associated with more elevated PGB. In addition to these two evidence-based predictions, we are also interested in determining if problematic gamers 
tend to be aware of their problematic behaviour or not. If we fail to find a difference between problematic and non-problematic gamers regarding self-awareness of problematic usage this would be an argument supporting the fact that the concerned gamers tend to deny their problematic gaming.

\section{Methods}

\section{Participants and Procedure}

The study invitation was distributed to 3000 individuals (aged 13 to 24) by post. The study sample was randomly selected from The Population Register Centre of Finland. Responses had to be submitted online. The inclusion criteria were: (1) being a Finnish-speaking person aged 13-24 and (2) having been involved in video game use during the last 3 months. Exclusion of all participants who had not played digital games regularly (i.e. the second inclusion criteria) was done during the data analytic process. Since the early onset of excessive and problematic behaviour during adolescence or young adulthood may also increase the likelihood of these problems later in life (e.g. Griffiths 2011), we focused the target group to include ages from 13 up to 24. A stratified sampling method was applied to obtain study participants from all age groups and both genders. The study data were collected in March 2014.

In total, 294 respondents completed the survey via a website in which 271 provided useful data for this study. From the total sample, 23 respondents were excluded from the study because of missing data or because they had not played digital games during the last 3 months. The average age of the participants was 18.7 years $(S D=3.45)$. More details of the study participants and their socio-demographic characteristics are described elsewhere (Männikkö et al. 2015).

\section{Ethics}

The study was made in accordance with the principles formulated in the Declaration of Helsinki. Cover letters were distributed by post, and responses could be given via a website. The participants completed an online survey. Individuals agreed to participate in the study through the 
information page. Concerning the participants aged 13-14, an information letter was sent to the parents or guardians, who then decided whether to provide their child with the information and link to take the online survey. Participation was voluntary. The participants' identification data were not collected. We were unable to contact 17 of the individuals selected because of incorrect addresses.

\section{Measures}

\section{Problematic Gaming Behaviour}

The seven-item version of the Gaming Addiction Scale (GAS) for adolescents was used in this study to assess problematic gaming among the adolescents. The validity of the scale was established in a previous study (Lemmens et al. 2009). Although the GAS was designed to screen for symptoms of gaming addiction among adolescents, it has also been successfully applied to a large age range of community participants (Festl, Scharkow, \& Quandt, 2013). The GAS was adapted from English to Finnish through a process of translation and retranslation. The researchers translated and produced the initial version of the instrument, which was then back-translated into English by a professional translator. Residual discrepancies were then discussed and resulted in the final Finnish version of the scale. Cronbach's alpha for the GAS in this study was 0.79 . The scale contains a set of items designed to detect excessive use of video games and addiction-like symptoms (e.g., cognitive and behavioural symptoms, mood modification, conflicts). Each item consisted of a problematic type of case, and respondents marked how often this had occurred over the past 6 months on a five-point Likert scale ("never", "rarely", "sometimes", "often" or "very often").

AQ3

The monothetic and polythetic approaches proposed by Lemmens et al. (2009) were used to identify PGB. When applying the monothetic approach (score $>2$ on all seven items), no case of PBG was identified. In contrast, relying on the polythetic approach (score $>2$ on at least four items) identified 24 participants as problematic gamers. 
Three items extracted from a study by Haagsma et al. (2012b) were used to measure self-awareness of problematic use, namely (1) "I think I spend too much time on gaming"; (2) "I think my gaming behaviour is problematic" and (3) "I think I'm going to seek help". The items were scored on a five-point Likert scale ranging from 1 (certainly not) to 5 (certainly). The items were interpreted so that values of 1 and 2 reflected an absence of awareness (code 0), a value of 3 reflected neither the presence nor the absence of awareness, and values of 4 and 5 reflected an awareness of problematic use.

\section{Game Genres}

The frequency of playing in different game categories was assessed on a five-point Likert scale ranging from (1) "never" to (5) "every day". To make sure that each of the categories proposed were clear to the participants, two game examples were given for each category. The game genres were determined based on previous categorisations (e.g., Elliott et al. 2012; Kuss and Griffiths 2012). The following categories were used: MMORPGs (e.g., World of Warcraft), massively multiplayer online games (MMOGs) (e.g., World of Tanks), roleplaying games RPGs (e.g., Skyrim), other forms of strategy games (e.g., real-time strategy such as StarCraft), platform games (e.g., Sonic), actionadventure games (e.g., Tomb Raider, Hitman), adventure games (e.g., Full Throttle or Indiana Jones), FPS (e.g., Battlefield, Counter Strike), fighting games (e.g., Street Fighter, Mortal Kombat), sports games (e.g., FIFA, NHL), music and party (e.g., SingStar, Rocksmith), driving simulation (e.g., World Rally Championship, F1), puzzle games (e.g., Candy Crush Saga), other simulation games (e.g., FlightGear), classic games (e.g., card (patience) games), mobile games (i.e., games such as Angry Birds played on a mobile device such as a phone, smartphone or PDA) and Facebook games (i.e., games played on Facebook such as FarmVille). The items were recoded so that values of 0 ("never") reflected "non-relevant game categories"; values of 2 and 3 ("every now and then"; "monthly") reflected "low involvement"; and values of 4 and 5 ("every week"; "daily") reflected "high involvement".

\section{Gaming Motives}


Gaming motives were assessed using a set of 14 items consisting of both items taken from previous studies and items generated for the purpose of the current study (Choi et al. 2004; Haagsma 2012a; LaRose and Eastin 2004). Each item started with the following phrase: "I use gaming ..." and was scored on a 5-point Likert scale (1 = "totally disagree", 3 = "neutral", 5 = "totally agree").

\section{Statistical Analysis}

Descriptive statistics were computed for the participants' demographics, weekly playing time, gaming genre usage and gaming motives. Nonparametric tests-the Mann-Whitney and Kruskal-Wallis-were performed to determine the association between game playing time and demographics (gender and age groups). These non-parametric tests were used because the data failed to follow a normal distribution. The Pearson coefficient was used to consider correlations between total GAS scores and weekly playing time. Principal component analysis (PCA) was used to explore the structure of the gaming genres and motives for data reduction purposes. Oblimin rotation was used because we did not expect the genres and motives to be independent. Two separate regression analyses were performed to determine predictors (gaming genres and motives) of problematic gaming behaviour (assessed with total GAS scores). The total GAS scores were used as a dependent variable in this model. Two distinct regression analyses were used to avoid including too many and interrelated variables in the same model. In addition, a dichotomous variable of PGB was used to describe distributions of gaming genres, motives and self-awareness of problematic gaming behaviour among participants displaying PGB. The Kruskal-Wallis test was also used to compare differences in problematic gaming scores and weekly gaming times at different self-awareness levels of problematic gaming. The statistical analyses were carried out using the SPSS statistical software package version 22. The level of significance was set at $p<0.05$.

\section{Results}

Sample Description 
Table 1 shows the frequency of digital gaming playing in relation to demographics, occupational status and educational level. The results from the Mann-Whitney test $(U=4209, p<0.001)$ revealed that the weekly amount of time spent playing (in hours) differed significantly between males $(M d n=11)$ and females $(M d n=2)$. In the whole sample, self-reported weekly time spent gaming ranged from less than one hour to $102 \mathrm{~h}$. Based on the Kruskal-Wallis test, no difference in mean playing time per week between different age groups appeared $\left(\chi^{2}=1.52, p=0.676\right)$. The results from the Mann-Whitney test $(U=978, p<0.001)$ indicated that the average digital game playing time per week was significantly higher for problematic players $(M d n=20)$ than for non-problematic players $(M d n=5)$. Additional analysis (Pearson correlations) also showed that playing time per week was positively correlated with GAS scores $(r=.49, p<0.05)$.

\section{Table 1}

Playing times per week (hours) as a function of characteristics of participants

\begin{tabular}{|c|c|c|c|c|}
\hline & $\mathbf{n}$ & percent & Mean & SD \\
\hline \multicolumn{5}{|l|}{ Gender $^{\mathrm{a}}$} \\
\hline a. Male & 137 & 52.5 & 16.6 & 16.9 \\
\hline b. Female & 124 & 47.5 & 5.8 & 9.6 \\
\hline Total & 261 & 100 & 11.5 & 14.9 \\
\hline \multicolumn{5}{|l|}{$\mathrm{Age}^{\mathrm{b}}$} \\
\hline a. $13-15$ & 70 & 26.9 & 11.4 & 16.1 \\
\hline b. $16-18$ & 59 & 22.7 & 13.9 & 17.9 \\
\hline c. $19-21$ & 62 & 23.8 & 11.9 & 13.1 \\
\hline d. $22-24$ & 69 & 26.5 & 9.3 & 12.2 \\
\hline Total & 260 & 100 & 11.5 & 14.92 \\
\hline \multicolumn{5}{|l|}{ Occupation } \\
\hline a. Full-time job & 21 & 8.1 & 6.7 & 6.5 \\
\hline \multicolumn{5}{|c|}{ apost hoc test showed that males spent more time playing than females } \\
\hline \multicolumn{5}{|c|}{$\begin{array}{l}{ }^{b} P o s t \text { hoc test showed no difference in time spent playing in function of } \\
\text { participant's age }\end{array}$} \\
\hline
\end{tabular}




\begin{tabular}{|c|c|c|c|c|}
\hline & $\mathbf{n}$ & percent & Mean & SD \\
\hline b. Part-time job & 7 & 2.7 & 8.0 & 12.3 \\
\hline $\begin{array}{l}\text { c. Unemployed or temporarily laid- } \\
\text { off }\end{array}$ & 15 & 5.8 & 13.5 & 13.0 \\
\hline d. Student & 204 & 78.5 & 11.9 & 15.6 \\
\hline e. Other & 13 & 5.0 & 11.8 & 16.3 \\
\hline Total & 260 & 100 & 11.5 & 14.9 \\
\hline \multicolumn{5}{|l|}{ Education level } \\
\hline a. Elementary school & 132 & 50.8 & 13.3 & 17.4 \\
\hline b. Secondary education & 43 & 16.5 & 9.8 & 10.1 \\
\hline c. Other vocational education & 4 & 1.5 & 7.2 & 9.8 \\
\hline d. Higher professional education & 14 & 5.4 & 9.8 & 11.8 \\
\hline e. University & 30 & 11.5 & 8.7 & 11.3 \\
\hline f. Other & 37 & 14.2 & 9.7 & 13.3 \\
\hline Total & 260 & 100 & 11.4 & 14.8 \\
\hline \multicolumn{5}{|c|}{ apost hoc test showed that males spent more time playing than females } \\
\hline \multicolumn{5}{|c|}{$\begin{array}{l}\text { bPost hoc test showed no difference in time spent playing in function of } \\
\text { participant's age }\end{array}$} \\
\hline
\end{tabular}

Figure 1 depicts the gaming preferences of the non-PGB participants. The most frequent gaming genre was "mobile" (74\%), followed by "puzzle" (72\%) and "platform" $(68 \%)$. The least popular category was "MMORPG" games (71\% of the non-PGB participants are not involved in playing MMORPG). Prevalence rates were evaluated from the games played at least sometimes within the last three months. Additional analyses done on the non-PGB sample showed that high involvement (i.e. reported frequency of weekly or daily gaming) was related to the following games: "mobile" (37\%), "FPS" (28\%) and "puzzle" (27\%). Gaming preferences of the PGB participants are shown in Fig. 2 . Participants displaying PGB reported interest (i.e. played at least sometimes in the last three months) in the following games: "RPG" (92\%), "puzzle" (79\%) and "FPS" (75\%). By contrast, the highest involvement frequency (i.e. reported frequency of weekly or daily 
gaming) of game types in the PGB group was related to the following games: "RPG" (42\%), "action-adventure" (29\%), "mobile" (29\%), "MMORPG" (25\%), "strategy" (25\%) and "puzzle" (25\%).

\section{Fig. 1}

Gaming preferences among the non-PGB participants $(n=228-239)$

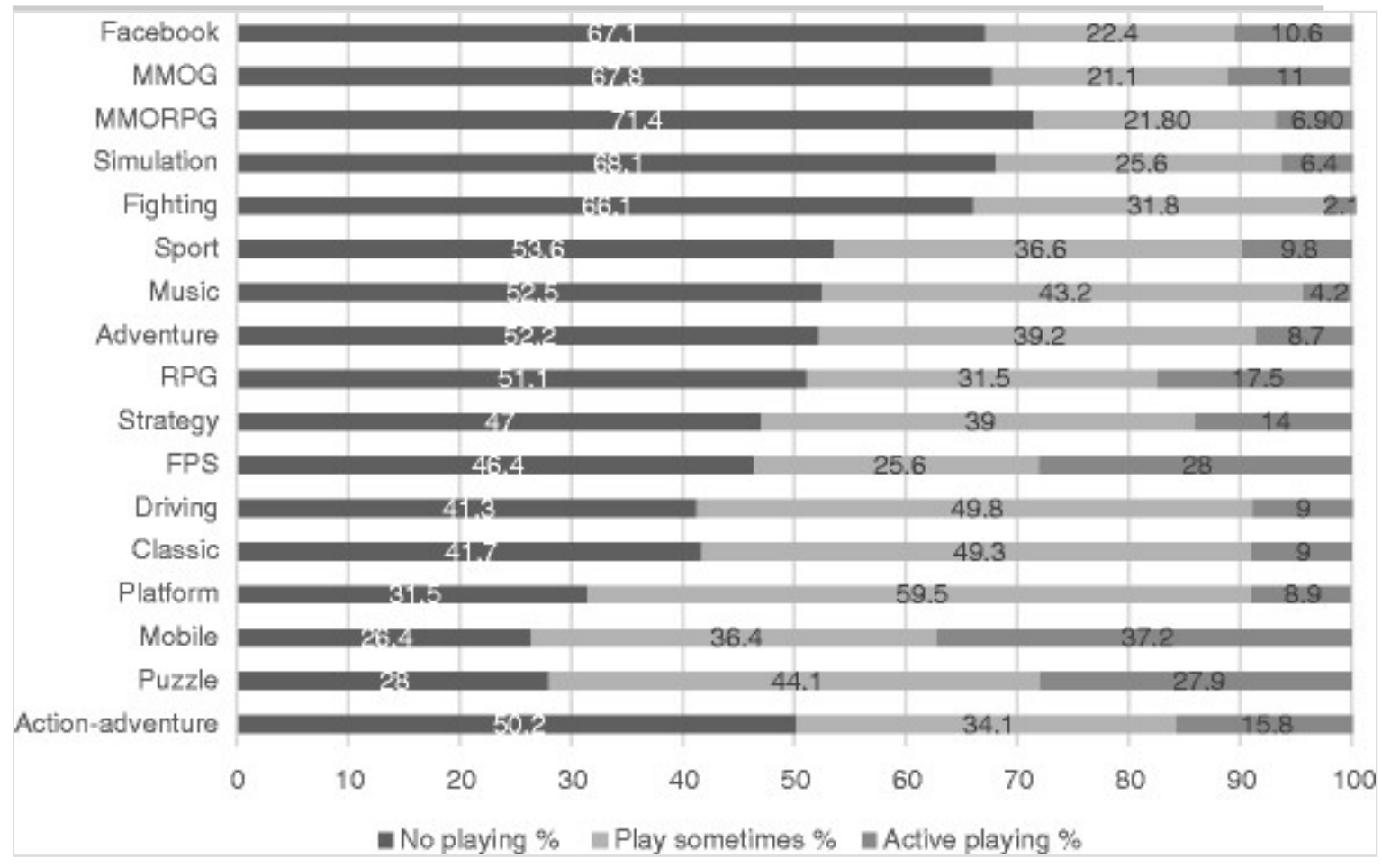

\section{Fig. 2}

Gaming preferences among the PGB group $(n=24)$

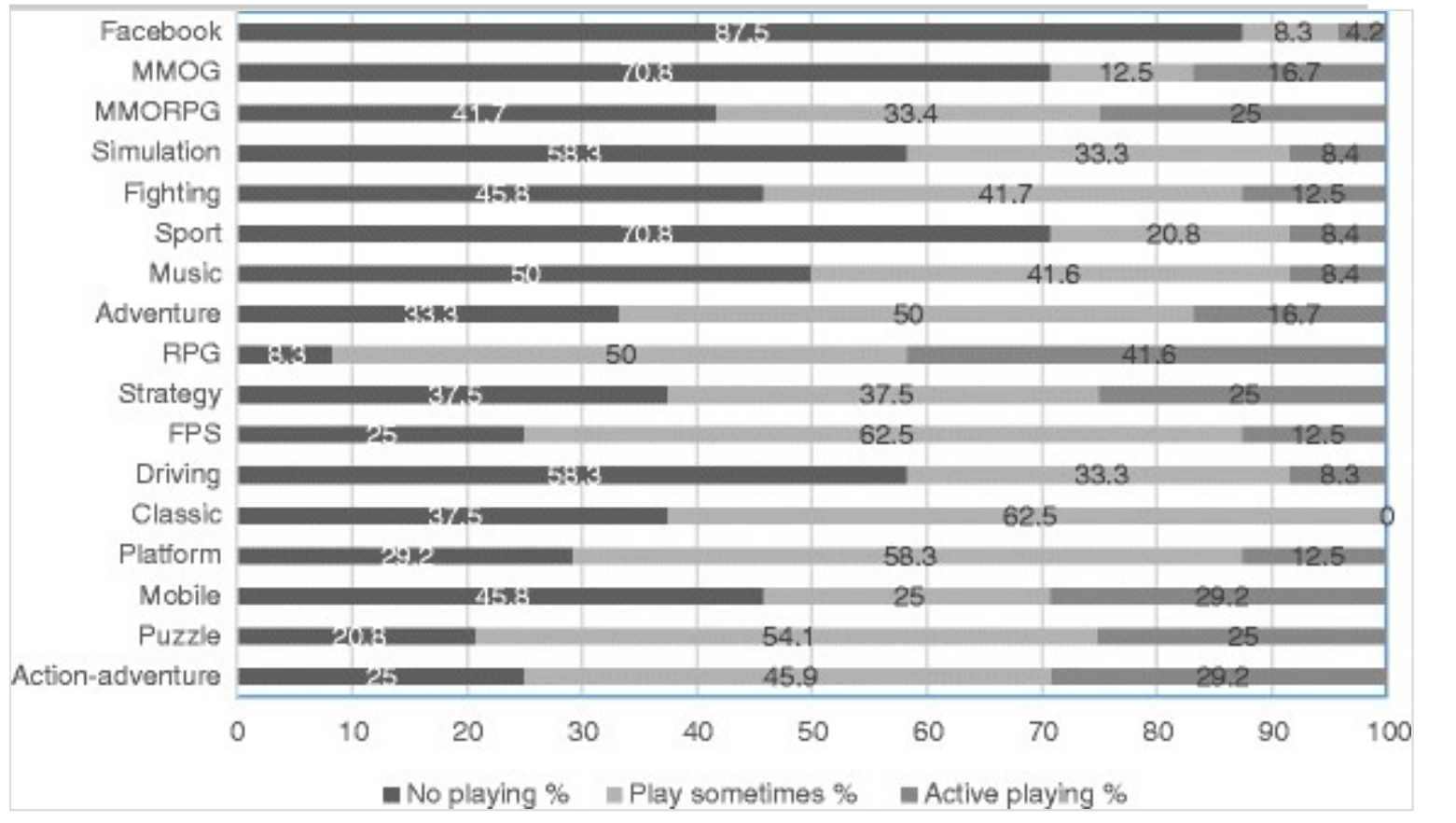


Table 2 shows the respondents' motives for playing digital games. The three most frequent motives of both problematic and non-problematic gamers were related to pleasure, convenience, and relaxation.

Participants displaying PGB more frequently cited as their motives escapism, skill development, competition, and social interaction. Each participant who gave an "agree or totally agree" answer was considered to endorse this latter motive.

\section{Table 2}

Motives for gaming (Base non-PGB $n=238$; PGB, $n=24$ )

\begin{tabular}{|l|l|l|}
\hline \multicolumn{1}{|c|}{ Motives } & $\begin{array}{c}\text { Non-PGB } \\
\mathbf{0}\end{array}$ & $\begin{array}{c}\text { PGB } \\
\mathbf{0}\end{array}$ \\
\hline It is an easy way to pass the time & 74.3 & 91.7 \\
\hline I enjoy doing it & 73.5 & 91.7 \\
\hline It is a way to relax & 60.6 & 95.6 \\
\hline It offers me excitement & 57.3 & 87.0 \\
\hline By playing I can learn new things & 49.7 & 83.4 \\
\hline I enjoy the competiveness of the game & 48.0 & 70.8 \\
\hline $\begin{array}{l}\text { I can experience and try things I can't find in the real } \\
\text { world }\end{array}$ & 46.7 & 83.3 \\
\hline I want to develop as a player & 39.5 & 87.5 \\
\hline It enables me to try out new identities & 34.5 & 50.0 \\
\hline I can meet new people & 19.6 & 54.1 \\
\hline $\begin{array}{l}\text { It offers a way to participate in different social } \\
\text { communities and discussions }\end{array}$ & 19.2 & 54.2 \\
\hline I can escape my worries & 19.2 & 54.2 \\
\hline I can escape from the real world & 16.7 & 34.8 \\
\hline It makes me feel less lonely & 13.8 & 58.3 \\
\hline
\end{tabular}

\section{Data Grouping}

PCA was performed to identify broader types of related gaming genres. Prior to this, we excluded MMOG and Facebook from the analysis 
because this genre was only reported by a minority of the participants in both the total sample and the subgroup of participants displaying PGB. The analysis suggested the extraction of four factors. The loading of each item was greater than .30. The sums of squared loading were 4.19, $1.94,1.60$ and 1.08, respectively. The four factors accounted for $63.20 \%$ of the variance (Component 1: $27.96 \%$, Component 2: $12.97 \%$, Component 3: $10.68 \%$ and Component $4: 7.23 \%$ ). The first component grouped six types of games and was related to the group of games encompassing role-playing, progression (e.g., character development), action and strategy features. This component included game genres such as MMORPG, RPG, action-adventure, strategy, FPS and adventure. The second component corresponded to sports or simulation games and included three items (sports, driving or simulation). The third component involved problem-solving/puzzles, logical thinking and regrouped three items (puzzle, classic and mobile phone). The last component was related to short-term, on-screen character actions, which are typically competitive and entertainment features (included two items: fighting and music). One gaming genre (platform) was removed after the analysis, as it loaded similarly on two components (1 and 3).

The second PCA was conducted to identify categories of gaming motives. The analysis resulted in four components. The sums of squared loading were $6.63,1.56,1.29$ and 1.08 , respectively. The four components accounted for $75.62 \%$ of the variance (Component 1 : 47.37\%, Component 2: 11.19\%, Component 3: 9.27\% and Component 4: 7.78\%). Based on this analysis, four distinct motives-(1) experienceimmersion (consisting of three items referring to the importance of seeking experiences or excitement and trying different identities); (2) entertainment-achievement (consisting of four items portraying a way to relax or pass the time and to enjoy competitiveness); (3) social (consisting of three items that corresponded to feeling less lonely, preferences of social interaction and communication through gaming); and (4) escapism (two items that corresponded to using the game to escape from reality and worries)-were retained for subsequent analyses and formed by combining related sub-items into sum variables. Two motive items ("I want to develop as a player" and "by playing I can learn new things") were excluded from the analysis because of the low 
component loadings (lower than 0.50 ) and they loaded similarly with two factors.

\section{Gaming Genres and Motives Associated with Problematic Gaming Behaviour}

Two distinct regression analyses were performed to determine which independent predictors contribute to PGB. Independent variables included in the first regression were gaming genres (four variables), whereas independent variables included in the second regression were gaming motives (four variables). Table 3 shows the results of both regression analyses. The first regression analysis indicated that usage of the game categories of role-playing, progression (e.g., character development), action and strategy was a significant predictor of PGB. The variable in this model explained $17 \%$ of the variance $(p<.001)$. The second regression analysis showed that entertainment-achievement, social and escapism motives significantly contributed to explaining PGB. The motive of experience-immersion was not a significant predictor. As a whole, these variables explained $34 \%$ of the variance $(p<.001)$.

\section{Table 3}

Multiple linear regression analysis with problematic gaming scores as the dependent variable

\begin{tabular}{|c|c|c|c|c|c|c|}
\hline Independent Variable & $\begin{array}{l}\mathbf{N} \\
\text { Valid }\end{array}$ & B & SE & Beta & $\mathbf{t}$ & $\mathbf{p}$ \\
\hline Gaming Genres & 259 & & & & & \\
\hline Role-Action-Adventure & & .34 & .05 & .42 & 6.72 & .000 \\
\hline SportS-Simulation & & -.13 & .11 & -.07 & -1.14 & .254 \\
\hline Puzzle-Classic & & -.02 & .09 & -.01 & -.31 & .753 \\
\hline Fighting-Music & & .36 & .20 & .10 & 1.79 & .074 \\
\hline Motives for playing games & 264 & & & & & \\
\hline Experience-immersion & & .06 & .07 & .05 & .84 & .400 \\
\hline $\begin{array}{l}\text { Entertainment and } \\
\text { achievement }\end{array}$ & & .22 & .07 & .19 & 3.06 & .002 \\
\hline
\end{tabular}

Significant results are in boldface 


\begin{tabular}{|l|c|c|c|c|c|c|}
\hline Independent Variable & $\begin{array}{c}\mathbf{N} \\
\text { Valid }\end{array}$ & $\mathbf{B}$ & $\mathbf{S E}$ & $\mathbf{B e t a}$ & $\mathbf{t}$ & $\mathbf{p}$ \\
\hline Social & & $\mathbf{. 2 9}$ & $\mathbf{. 0 7}$ & $\mathbf{. 2 3}$ & $\mathbf{3 . 8 8}$ & $\mathbf{. 0 0 0}$ \\
\hline Escapism & & $\mathbf{. 5 5}$ & $\mathbf{. 1 0}$ & $\mathbf{. 3 0}$ & $\mathbf{5 . 4 7}$ & $\mathbf{. 0 0 0}$ \\
\hline
\end{tabular}

Significant results are in boldface

\section{Self-Awareness of PGB}

Of all the respondents, $16.5 \%(n=45)$ reported spending too much time with digital games. Regarding problematic players, 33\% $(n=8)$ reported spending too much time playing digital games. Overall, only $3.6 \%(n=10)$ of the respondents reported being aware of their excessive use of digital games. The results also revealed that $12.5 \%$ $(n=3)$ of the problematic players recognised themselves as being characterised by PGB. Of all the respondents, $0.8 \%(n=2)$ reported being in need of external support to manage their PGB.

Comparisons of time spent playing and problem gaming symptoms as a function of awareness of PGB, based on Kruskal Wallis tests, are shown in Table 4. According to this analysis, problematic gaming scores and weekly gaming times differed significantly according to self-awareness of PGB, with the highest rank of problem awareness being associated with the highest average time spent playing and problem gaming symptoms.

\section{Table 4}

Kruskal Wallis test results on self-awareness of PGB levels according to the PGI playing time

\begin{tabular}{|c|c|c|c|c|c|c|c|c|}
\hline & & \multicolumn{5}{|c|}{ GAS scores } & \multicolumn{2}{|r|}{ Weekly } \\
\hline \multicolumn{2}{|c|}{ Variables } & & Mean & & $\gamma^{2}$ & & & Mean \\
\hline \multirow{3}{*}{$\begin{array}{l}\text { 'I think I } \\
\text { spend too } \\
\text { much time } \\
\text { on gaming' }\end{array}$} & $\begin{array}{l}0 \\
\text { irrelevant }\end{array}$ & 179 & 114.89 & \multirow{3}{*}{2} & \multirow{3}{*}{31.73} & \multirow{3}{*}{$\begin{array}{l}< \\
0.001\end{array}$} & 173 & 110.77 \\
\hline & 1 neutral & 44 & 165.40 & & & & 44 & 165.72 \\
\hline & $\begin{array}{l}2 \\
\text { relevant }\end{array}$ & 42 & 176.24 & & & & 44 & 175.83 \\
\hline
\end{tabular}




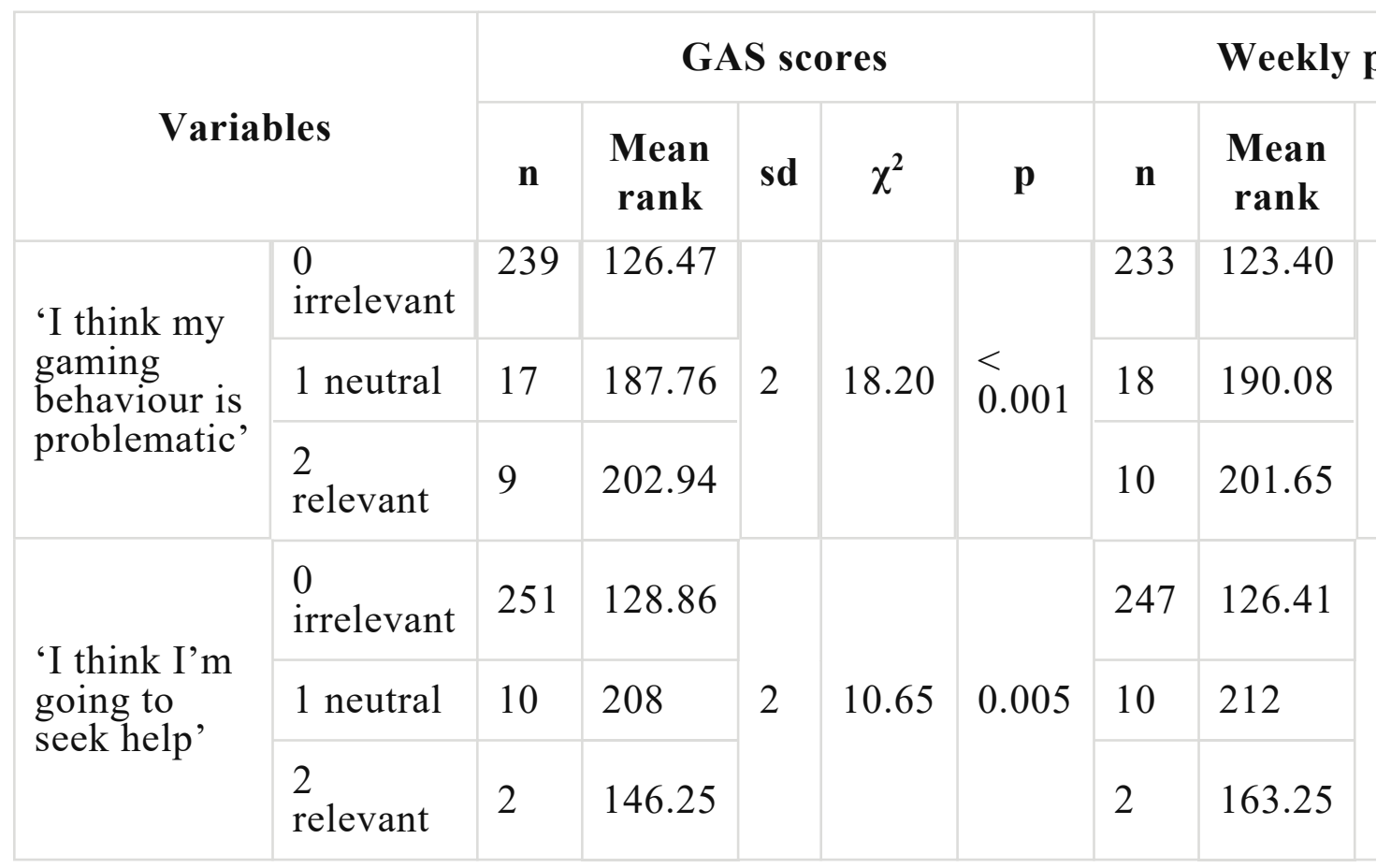

\section{Discussion and Conclusions}

The aim of the study was to explore the relations between PGB, gaming motives, gaming types and self-awareness of PGB in a sample of Finnish adolescents and young adults.

As expected, PGB was significantly associated with a group of games encompassing role-playing, progression, action and strategy components. These results were in line with previous evidence and our hypotheses that Roleplaying games (both RPG and MMORPG) are more prone to contribute to PGB (Lee, 2007; Kuss et al. 2012; Smyth 2007). These results are in line with recent data showing the importance of game genre in the development of PGB (Donati et al. 2015). The video games that in the present study predict PGB are characterised by specific structural characteristics (e.g., complex advancement/reward system, regular updates involving "never-ending" content, element of immersion or role-play) that are known to promote excessive or uncontrolled patterns of playing (Billieux et al. 2014; King et al. 2010; Stetina et al. 2011) In contrast, the level of complexity and the involvement of social interaction required of game types such as platformer, simulation, sports, fighting and music (or 
rhythm) appears lower (e.g. Granic et al. 2014), which could imply that they are less associated with PGB.

AQ4

The study results are consistent with previous data relating escapism and achievement motives (e.g., character and/or status progression) to PGB (Billieux et al. 2011; Billieux et al. 2013; Billieux et al. 2015c; Hull et al. 2013; Hellström et al. 2012; Kneer and Glock 2013; Yee 2006 ). Evidence is more mixed regarding social motives, as past studies have found them to be either vulnerability factors (Zanetta Dauriat et al. 2011) or protective factors (Hull et al. 2013) with regard to the development of PGB, although most studies have failed to identify a significant relation between social motives and PGB (see Billieux et al. 2014, for a review). In the current study, a social motive (i.e., "it makes me feel less lonely, I can meet new people and it offers a way to participate in different social communities and discussions") was associated with PGB. Accordingly, it could be argued that players preferring to seek socialising through the use of video games (or who need to because of restricted social capital) are more likely to display PGB. Alternatively, it can also be supposed that high involvement in video games is favoured because of peer pressure to maintain high involvement (e.g., when someone is a member of a "guild" or an alliance that regroups several gamers).

The current study also showed that only a minority of gamers displaying PGB are aware of their problematic involvement. In fact, only those who are at risk of becoming more severely dependent on gaming actually perceived themselves as having PGB. However, is it likely that young people consider media to have a stronger effect on others than on themselves. This effect is very robust, and is called the third-person effect (e.g. Davison 1983). Thus individual frequently deny video gaming as a potentially risky activity in contrast to more recognised problematic behaviour such as substance abuse.

This study has several limitations. Firstly, it is not possible to show causality or a developmental perspective in this study, because a crosssectional design was used. Second, the participants self-reported their gaming behaviour, which could have resulted in at least partly flawed 
answers (e.g., social desirability bias, lack of introspection on the part of the participants). Third, the response rate of the study is relatively low, implying that the sample studied may not be representative of the entire population. Fourth, even if the design of the present study did rely on a randomly selected national sampling, it appears that the final sample (i.e. after retaining only video gamers) mainly consisted of school and university students. Finally, gaming motives were measured with items designed in the framework of the current study, and not with a validated questionnaire. However, this choice was made as there is no existing validated questionnaire suited for assessment of the various motives that can be linked to the comprehensive list of video games used in our study.

To conclude, this study confirms and extends previous evidence regarding gaming preferences and gaming motives, and brings original results with regard to self-awareness of PGB. However, in light of the limitations raised, future studies should include longitudinal data to generate evidence for a causal hypotheses, and they should also include bigger representative (i.e., non-self-selected) samples.

\section{Acknowledgements}

The authors express appreciation to the Finnish Association for Substance Abuse Prevention and the National Institute for Health and Welfare in Finland for their support of the study.

Compliance with Ethical Standards

Conflict of Interest None of the authors has a conflict of interest to declare.

\section{References}

AQ5

Achterbosch, L., Pierce, R. \& Simmons, G. (2008). Massively Multiplayer Online Role-Playing Games: The past, present, and future. ACM Computers in Entertainment, 5(4). 
American Psychiatric Association (APA). (2013). Diagnostic and statistical manual of mental disorders (5th ed.). Washington, DC.

Bartle, R.A. (1996). Hearts, Clubs, Diamonds, Spades: Players Who Suit MUDs. Journal of MUD Research, 1(1) Retrieved from: http://mud.co.uk/richard/hcds.htm

Billieux, J., Chanal, J., Khazaal, Y., Rochat, L., Gay, P., Zullino, D., \& Van Der Linden, M. (2011). Psychological predictors of problematic involvement in massively multiplayer online role playing games (MMORPG): illustration in a sample of male cybercafés players. Psychopathology, 44(33), 165-171.

Billieux, J., Van der Linden, M., Achab, S., Khazaal, Y., Paraskevopoulos, L., Zullino, D., \& Thorens, G. (2013). Why do you play world of Warcraft? An in-depth exploration of self-reported motivations to play online and in-game behaviours in the virtual world of Azeroth. Computers in Human Behavior, 29(1), 103-109.

Billieux, J., Deleuze, J., Griffiths, M. D., \& Kuss, D. J. (2014). Internet addiction: the case of massively multiplayer online role playing games. In N. El-Guebaly, M. Galanter, \& G. Carrá (Eds.), The Textbook of Addiction Treatment: International Perspectives (Vol. 30, pp. 1515-1525). New York: Springer.

Billieux, J., Philippot, P., Schmid, C., Maurage, P., de Mol, J., \& Van der Linden, M. (2015a). Is dysfunctional use of the mobile phone a behavioural addiction? Confronting symptom-based versus process-based approaches. Clinical Psychology \& Psychotherapy, 22 (5), 460-468.

Billieux, J., Schimmenti, A., Khazaal, Y., Maurage, P., \& Heeren, A. (2015b). Are we overpathologizing everyday life? A tenable blueprint for behavioral addiction research. Journal of Behavioral Addictions, 4, 119-123.

Billieux, J., Thorens, G., Khazaal, Y., Zullino, D., Achab, S., \& Van der Linden, M. (2015c). Problematic involvement in online games: a 
cluster analytic approach. Computers in Human Behavior, 43, 242 -250 .

Charlton, J., \& Danforth, I. (2007). Distinguishing addiction and high engagement in the context of online game playing. Computers in Human Behavior, 23(3), 1531-1548.

Choi, J. H., Watt, J. H., Dekkers, A. C. \& Park, S. (2004). Motives of Internet uses: Crosscultural Perspective - the US, the Netherlands, and $S$. Korea. Retrieved from http://www.allacademic.com/meta/p112833_index.html .

Cole, H., \& Griffiths, M. D. (2007). Social interactions in massively multiplayer online role-playing gamers. Cyberpsychology \& Behavior, 10(4), 575-583.

Davison, W. P. (1983). The third-person effect in communication. Public Opinion Quarterly, 47, 1-15.

Donati, M. A., Chiesi, F., Ammannato, G., \& Primi, C. (2015). Versatility and addiction in gaming: the number of video-game genres played is associated with pathological gaming in male adolescents. Cyberpsychology, Behavior and Social Networking, 18 (2), 129-132.

Eichenbaum, A., Kattner, F., Bradford, D., Gentile, D. A., Choo, H., et al. (2015). The role of game genres and the development of internet gaming disorder in school-aged children. Journal of Addictive Behaviors Therapy \& Rehabilitation, 4, 3.

Elliott, L., Golub, A., Ream, G., \& Dunlap, E. (2012). Video game genre as a predictor of problem use. Cyberpsychology, Behavior and Social Networking, 15(3), 155-161.

Gentile, D. (2009). Pathological video-game use among youth ages 8 to 18: a national study. Psychological Science, 20(5), 594-602. 
Granic, I., Adam, L., \& Engels, R. C. M. E. (2014). The benefits of playing video games. American Psychologist, 69(1), 66-78.

Griffiths, M. (2000). Does internet and computer "addiction" exist? Some case study evidence. Cyber Psychology \& Behavior., 3(2), 211 -218 .

Griffiths, M. D. (2011). Behavioural addiction: the case for a biopsychosocial approach. Transgressive. Culture, 1(1), 7-28.

Griffiths, M. D., Kuss, D. J., \& King, D. L. (2012). Video game addiction: past, present and future. Current Psychiatry Reviews, 8 , $308-318$.

Griffiths, M. D., van Roij, A., Kardefelt-Winther, D., Starcevic, V., Király, O., Pallesen, S., Müller, K., Dreier, M., Carras, M., Prause, N., King, D., Aboujaoude, E., Kuss, D. J., Pontes, H., LopezFernandez, O., Nagygyorgy, K., Achab, S., Billieux, J., Quandt, T., Carbonell, X., Ferguson, C., Hoff, R., Derevensky, J., Haagsma, M., Delfabbro, P., Coulson, M., Hussain, Z., \& Demetrovics, Z. (2016). Working towards an international consensus on criteria for assessing internet gaming disorder: a critical commentary on Petry et al. (2014). Addiction, 111, 167-178.

Grüsser, S. M., Thalemann, R., \& Griffiths, M. D. (2007). Excessive computer game playing: evidence for addiction and aggression? Cyber Psychology \& Behavior, 10(2), 290-292.

Haagsma, M.C. (2012a). Understanding problematic game behavior. Prevalence and the role of social cognitive determinants. (Doctoral dissertation) University of Twente. Retrieved from http://www.utwente.nl/bms/pgt/bestanden/haagsmaproefschrift.pdf

Haagsma, M. C., Pieterse, M. E., \& Peters, O. (2012b). The prevalence of problematic video gamers in the Netherlands. Cyberpsychology, Behavior and Social Networking, 15(3), 162-168. 
Hellström, C., Nilsson, K. W., Leppert, J., \& Åslund, C. (2012). Influences of motives to play and time spent gaming on the negative consequences of adolescent online computer gaming. Computers in Human Behavior, 28(4), 1379-1387.

Hilgard, J., Engelhardt, C. R., \& Bartholow, B. D. (2013). Individual differences in motives, preferences, and pathology in video games: the gaming attitudes, motives, and experiences scales (GAMES). Frontiers in Psychology, 4, 608.

Hull, D. C., Williams, G. A., \& Griffiths, M. D. (2013). Video game characteristics, happiness and flow as predictors of addiction among video game players: a pilot study. Journal of Behavioral Addictions, 2(3), 145-152.

Kardefelt-Winther, D. (2014). The moderating role of psychosocial well-being on the relationship between escapism and excessive online gaming. Computers in Human Behavior, 38, 68-74.

King, D. L., Delfabbro, P., \& Griffiths, M. D. (2009). The psychological study of video game players: methodological challenges and practical advice. International Journal of Mental Health and Addiction, 7(4), 555-562.

King, D. L., Delfabbro, P., \& Griffiths, M. D. (2010). Video game structural characteristics: a new psychological taxonomy. International Journal of Mental Health and Addiction, 8, 90-106.

King, D. L., Haagsma, M. C., Delfabbro, P. H., Gradisar, M., \& Griffiths, M. D. (2013). Toward a consensus definition of pathological video-gaming: a systematic review of psychometric assessment tools. Clinical Psychology Review, 33, 331-342.

Kneer, J., \& Glock, S. (2013). Escaping in digital games: the relationship between playing motives and addictive tendencies in males. Computers in Human Behavior, 29(4), 1415-1420. 
Ko, C.-H., Yen, J. Y., Chen, S. H., Wang, P. V., Chen, C. S., \& Yen, C. F. (2014). Evaluation of the diagnostic criteria for internet gaming disorder in the DSM-5 among young adults in Taiwan. Journal of Psychiatric Research, 53, 103-110.

Kuss, D. J., \& Billieux, J. (2017). Technological addictions: conceptualisation, measurement, etiology and treatment. Addictive Behaviors, 64, 231-233.

Kuss, D. J., \& Griffiths, M. D. (2012). Internet gaming addiction: a systematic review of empirical research. International Journal of Mental Health and Addiction, 10, 278-296.

Kuss, D. J., Louws, J., \& Wiers, R. W. (2012). Online gaming addiction? Motives predict addictive play behavior in massively multiplayer online role-playing games. Cyberpsychology, Behavior and Social Networking, 15(9), 480-485.

Kuss, D. J., van Rooij, A. J., Shorter, G. W., Griffiths, M. D., \& van de Mheen, D. (2013). Internet addiction in adolescents: prevalence and risk factors. Computers in Human Behavior, 29(5), 1987-1996.

Kuss, D. J., Griffiths, M. D., Karila, L., \& Billieux, J. (2014). Internet addiction: a systematic review of epidemiological research for the last decade. Current Pharmaceutical Design, 20(25), 4026 -4052 .

LaRose, R., \& Eastin, M. S. (2004). A social cognitive theory of internet uses and gratifications: toward a new model of media attendance. Journal of Broadcasting \& Electronic Media, 48(3), 358 -377 .

Lee, M. S., Ko, Y. H., Song, H. S., Kwon, K. H., Lee, H. S., Nam, M., \& Jung, I. K. (2007). Characteristics of internet use in relation to game genre in Korean adolescents. Cyber Psychology \& Behavior, $10,278-285$. 
Lemmens, J. S., \& Hendriks, S. J. (2016). Addictive online games: examining the relationship between game genres and internet gaming disorder. Cyberpsychology, Behavior and Social Networking, 19(4), 270-276.

Lemmens, J. S., Valkenburg, P. M., \& Peter, J. (2009). Development and validation of a game addiction scale for adolescents. Media Psychology, 12(1), 77-95.

Männikkö, N., Billieux, J., \& Kääriäinen, M. (2015). Problematic digital gaming behavior and its relation to the psychological, social and physical health of Finnish adolescents and young adults. Journal of Behavioral Addictions, 4(4), 281-288.

Mäyrä, F. \& Ermi, L. (2014). The Finnish Player Barometer 2013. University of Tampere.

Nagygyörgy, K., Urbán, R., Farkas, J., Griffiths, M. D., Zilahy, D., Kökönyei, G., Mervó, B., Reindl, A., Ágoston, C., Kertész, A., Harmath, E., Oláh, A., \& Demetrovics, Z. (2013). Typology and sociodemographic characteristics of massively multiplayer online game players. International Journal of Human Computer Interaction, 29(3), 192-200.

Petry, N. M., \& O'Brien, C. P. (2013). Internet gaming disorder and the DSM-5. Addiction, 108(7), 1186-1187.

Petry, N. M., Rehbein, F., Gentile, D. A., Lemmens, J. S., Rumpf, H. J., Mößle, T., Bischof, G., Tao, R., Fung, D. S., Borges, G., Auriacombe, M., González Ibáñez, A., Tam, P., \& O’Brien, C. P. (2014). An international consensus for assessing internet gaming disorder using the new DSM-5 approach. Addiction, 109(9), 1399 -1406 .

Rehbein, F., \& Mößle, T. (2013). Video game and internet addiction: is there a need for differentiation? Journal of Addiction Research and Practice, 59(3), 129-142. 
Rehbein, F., Kliem, S., Baier, D., Mößle, T., \& Petry, N. M. (2015).

Prevalence of internet gaming disorder in German adolescents:

diagnostic contribution of the nine DSM-5 criteria in a state-wide representative sample. Addiction, 110(5), 842-851.

Smyth, J. (2007). Beyond self-selection in video game play: an experimental examination of the consequences of massively multiplayer online role-playing game play. Cyber Psychology \& Behavior, 10(5), 717-721.

Stetina, B. U., Kothgassner, O. D., Lehenbauer, M., \& KryspinExner, I. (2011). Beyond the fascination of online-games: probing addictive behavior and depression in the world of online-gaming. Computers in Human Behavior, 27, 473-479.

Thorens, G., Achab, S., Billieux, J., Khazaal, Y., Khan, R., Pivin, E., Gupta, V., \& Zullino, D. (2014). Characteristics and treatment response of self-identified problematic internet users in a behavioral addiction outpatient clinic. Journal of Behavioral Addictions, 3(1), $78-81$.

van Rooij, A. J., \& Prause, N. (2014). A critical review of "internet addiction" criteria with suggestions for the future. Journal of Behavioral Addictions, 3(4), 203-213.

Van Rooij, A. J., Van Looy, J., \& Billieux, J. (2016). Internet gaming disorder as a formative construct: implications for conceptualization and measurement. Psychiatry and Clinical Neurosciences. doi: 10.1111/pcn.12404 .

Yee, N. (2006). Motivations for play in online games. Cyberpsychology \& Behavior, 9(6), 772-775.

Zanetta Dauriat, F., Zermatten, A., Billieux, J., Thorens, G., Bondolfi, G., Zullino, D., \& Khazaal, Y. (2011). Motivations to play specifically predict excessive involvement in massively multiplayer online role-playing games: evidence from an online survey. European Addiction Research, 17(4), 185-189. 
${ }^{1}$ MUD is a text-based adventure game that is a precursor to today's MMORPGs. MUD was one of the first online games. 